\title{
COVID-19 in a Down Syndrome Newborn
}

\author{
Gabriela Caroline Lobato Pontes ${ }^{\mathrm{a}, \mathrm{i}}$, Ariella Cristina Rego Lobato ${ }^{\mathrm{b}}$, \\ Samela Miranda da Silvac ${ }^{c}$ Daniel Figueiredo Alves da Silvad, \\ Alexandre Ferreira da Silva ${ }^{d}$, Rodrigo Santiago Barbosa Rocha ${ }^{\mathrm{e}}$, \\ Bianca Duarte de Oliveira ${ }^{\text {, Tallita Olga Calvinho Martins }}{ }^{\mathrm{f}}$, \\ Aurimery Gomes Chermont ${ }^{g}$, Katiane da Costa Cunha ${ }^{\mathrm{h}}$
}

\begin{abstract}
A 36-week premature newborn with trisomy 21 , had a fever, runny nose and mild dyspnea at 27 days old. Parents had flu-like symptoms. He was admitted to intensive care unit (ICU), in isolation with support therapy. His reverse transcription-polymerase chain reaction (RT-PCR) test for coronavirus disease 2019 (COVID-19) was positive. He had leukopenia and lymphopenia and increased C-reactive protein (CRP) levels, associated with mixed and interstitial opacities on chest radiography. Antibiotic therapy was performed with ampicillin and gentamicin for 10 days. He had improvement of symptoms, with worsening of CRP levels. On the 11th day of hospitalization antibiotic therapy was replaced by clarithromycin, which was performed for 5 days, with laboratory improvement after introduction. Chest computed tomography (CT) showed bilateral ground-glass lesions. He had a good recovery and was discharged from hospital with 17 days of hospitalization.
\end{abstract}

Keywords: Down syndrome; Coronavirus infections; Neonatology

\footnotetext{
Manuscript submitted June 28, 2020, accepted July 15, 2020

Published online November 3, 2020

aPediatrics Residency Program, Federal University of Para, Guama, Belem-PA 66075-110, Brazil

bPhysiotherapy, Intensive Care, Neonatology and Pediatrics, Faculdade Inspirar, Rua Bernal do Couto 229, Belem-PA 66055-080, Brazil

cPathology of Tropical Diseases, Federal University of Para, Tropical Medicine Nucleus, Av. Generalissimo Deodoro 92, Belem-PA 66055-240, Brazil

${ }^{\mathrm{d}}$ Health Education in the Amazon, State University of Para, Campus II/Belem, Tv. Perebebui 2623, Marco, Belem-PA 66095-661, Brazil

${ }^{\mathrm{e}}$ Human Movement Science, State University of Para, Campus II/Belem, Tv. Perebebui 2623, Marco, Belem-PA 66095-661, Brazil

${ }^{\mathrm{f} N e o n a t o l o g y}$ Residency Program, Santa Marcelina Hospital, R. Santa Marcelina 177, Vila Carmosina, Sao Paulo-SP 08270-070, Brazil

${ }^{g}$ Collective Health, Federal University of Sao Paulo, R. Sena Madureira 1500, Vila Clementino, Sao Paulo-SP 04021-001, Brazil

hBehavior Theory and Research, State University of Para, Campus VIII/Maraba, Av. Hileia, Agropolis do Incra s/n-Amapa, Maraba-PA 68502-100, Brazil ${ }^{\mathrm{i}}$ Corresponding Author: Gabriela Caroline Lobato Pontes, Pediatrics Residency Program, Federal University of Para, Augusto Correa 1, Guama, Belem-PA 66075-110, Brazil. Email: gabrielaclpontes@gmail.com
}

doi: https://doi.org/10.14740/ijcp396

\section{Introduction}

The new coronavirus, known as severe acute respiratory syndrome coronavirus 2 (SARS-CoV-2), is a ribonucleic acid (RNA) virus and is responsible for causing coronavirus disease 2019 (COVID-19). In children, including newborns, the disease has been presenting as mild or even asymptomatic, probably due to immune system immaturity $[1,2]$. Transmission occurs horizontally, by aspiration of droplets or aerosols [3], the possibility of transplacental transmission has been raised $[4,5]$.

Complications of the new coronavirus are associated with an immune response exacerbation, known as "cytokine storm", leading to acute respiratory distress syndrome, thromboembolism and multiple organ failure [6, 7]. Systemic inflammatory response syndrome secondary to COVID-19 may also occur in healthy children [8].

Down syndrome or trisomy 21 is a genetic disorder that has been associated with an overactivation of interferon, increased levels of inflammatory cytokines and chronic immune dysregulation, so it could lead to development of a more exacerbated condition when associated with COVID-19 involving a prolonged and intense cytokine storm [9]. Therefore, the objective of the study is to report a case study in a newborn patient with Down syndrome who acquired COVID-19.

Information contained in this work was obtained by reviewing medical records (evolution of health professionals, laboratory results and imaging tests) of a newborn admitted to intensive care unit (ICU) at the end of April 2020, in the city of Belem, Amazon region of Brazil.

\section{Case Report}

\section{Birth information}

The newborn of this study was 36 -week premature and male. $\mathrm{He}$ was the fourth pregnancy of 42-year-old mother and 45 -year-old father, who had two previous abortions and performed prenatal care without complications. Parents were not related. First trimester morphological ultrasound record showed increased nuchal translucency. He was born by ce- 
Table 1. Laboratory Findings

\begin{tabular}{|c|c|c|c|c|c|}
\hline Day of hospitalization & 1 & 4 & 11 & 13 & 16 \\
\hline White blood cells (cells $/ \mathrm{mm}^{3}$ ) & 3,630 & 5,920 & 16,030 & 8,560 & 8,100 \\
\hline Lymphocytes (cells/mm³) & 1,235 & 3,196 & 6,412 & 4,314 & 5,589 \\
\hline Platelets (cells/mm³) & 271,000 & 397,000 & 576,000 & 510,000 & 450,000 \\
\hline C-reactive protein (mg/dL) & 19.7 & 5.6 & 59.5 & 12.8 & 0.9 \\
\hline Aspartate transaminase $(\mathrm{mg} / \mathrm{dL})$ & & & & 27 & 26 \\
\hline Alanine aminotransferase $(\mathrm{mg} / \mathrm{dL})$ & & & & 18 & 13 \\
\hline D-dimer (ng/dL) & & & & 806 & 552 \\
\hline Bacteria blood culture & Negative & & Negative & & \\
\hline
\end{tabular}

sarean section and was premature due to fetal centralization, cried at birth, Apgar score was 8 at 2 min and 9 at 5 min. His head circumference was $33.5 \mathrm{~cm}$, the height was $45.5 \mathrm{~cm}$, and the weight was $2,950 \mathrm{~g}$. On physical examination, he had heart murmur and the following phenotypic characteristics of trisomy 21: small nose with a flattened bridge, a single line across the palm of the hand, epicanthal folds, up-slanting palpebral fissures, short neck and loose joints.

Echocardiogram performed 2 days after birth showed a patent foramen ovale and inter-atrial communication, both without systemic repercussions. Blood typing was A positive. He was discharged at $48 \mathrm{~h}$ of life, on the sixth day of life, he developed jaundice (total bilirubin $16.5 \mathrm{mg} / \mathrm{dL}$; high intermediate risk zone) and needed to be readmitted to perform simple phototherapy for $48 \mathrm{~h}$, with improvement of the condition. He was discharged after that. He got confirmation of Down syndrome by karyotype exam when he was 2 months old.

\section{ICU admission data}

According to the parents' report, at 26 days old, he presented runny nose and sneezing. His parents also had those symptoms. The newborn has breastfed. At 27 days old, the parents noticed signs of mild respiratory distress and noticed an episode of fever $\left(38.3^{\circ} \mathrm{C}\right)$, which prompted them to take him to the maternity hospital for medical assistance, where he was hospitalized for 17 days. On physical examination, he was dyspneic with subcostal retraction, respiratory rate of 50 breaths per min, heart rate of 170 beats per min, oxygen saturation level of $99 \%$ and fever of $38.7{ }^{\circ} \mathrm{C}$. The hypothesis of late neonatal sepsis with pulmonary focus and COVID-19 infection were raised.

He was then admitted to the ICU, in isolation. Precautionary contact, droplets and aerosol precautions were performed. Empirical treatment with ampicillin $(300 \mathrm{mg} / \mathrm{kg} /$ day intravenous (IV)) and gentamicin (4 mg/kg/day IV) was performed for 10 days. There was no need for ventilatory support.

Laboratory tests showed leukopenia, lymphopenia and increased C-reactive protein CRP) levels (leukocytes 3,630 $\times$ $10^{3} / \mu \mathrm{L}$; lymphocytes $1,235 \times 10^{3} / \mu \mathrm{L}$; CRP $19.7 \mathrm{mg} / \mathrm{dL}$; respectively) (Table 1).

The admission radiological study of chest showed mixed interstitial and alveolar opacities with interstitial aspect scattered throughout the lungs, predominantly in the lower lobe of the right lung (Fig. 1).

He had no bacterial growth in blood culture. Reverse transcription-polymerase chain reaction (RT-PCR) test for COVID-19 in an oropharynx and nasopharynx swab was positive.

\section{Evolution and discharge}

He had remission of fever on the fourth day of hospitalization as shown by the thermal curve in Figure 2, as well as remission of respiratory distress. On the fifth day of hospitalization, he had conjunctival injection.

Laboratory controls also showed improvement (the fourth

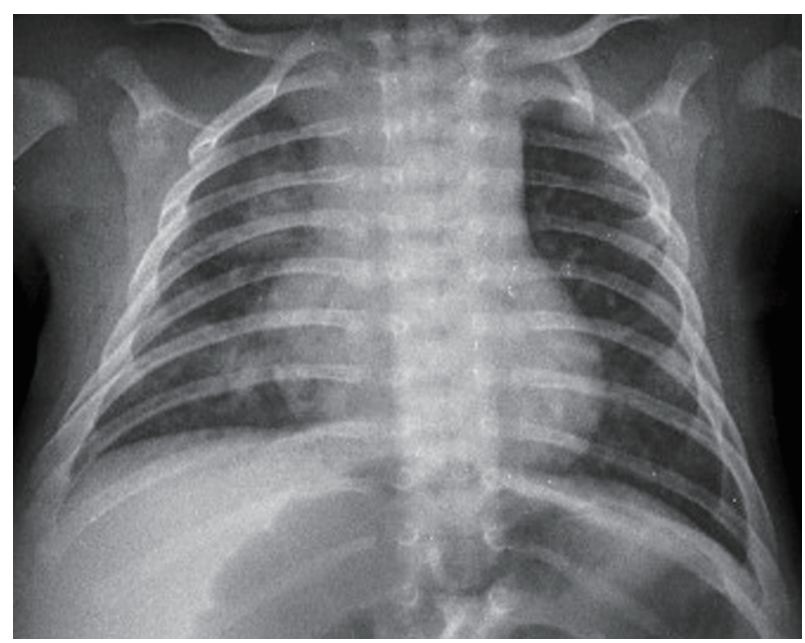

Figure 1. Chest X-ray. 


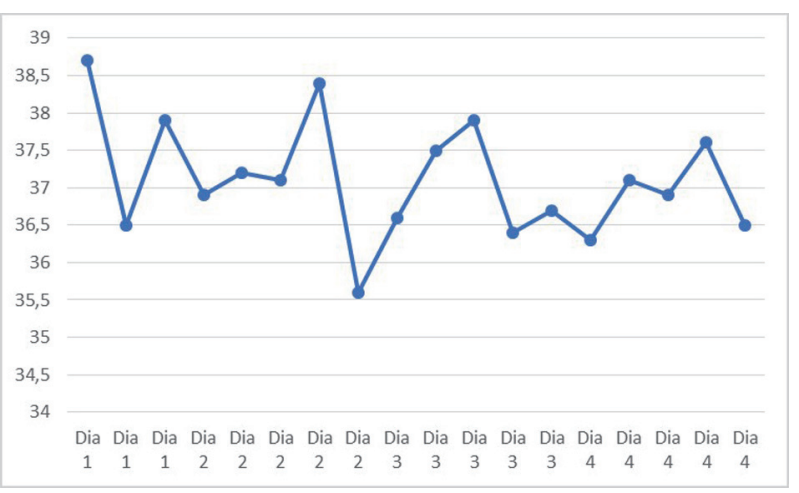

Figure 2. Thermal curve.

day of hospitalization: leukocytes $5,920 \times 10^{3} / \mu \mathrm{L}$; lymphocytes $3,196 \times 10^{3} / \mu \mathrm{L}$; CRP $5.6 \mathrm{mg} / \mathrm{dL}$ ).

On the ninth day of hospitalization, at 38 days old, the infant performed chest computed tomography (CT) which showed diffuse ground glass opacification, superimposed on peribronchovascular and reticular interstitial pulmonary involvement as well as thickening of some interlobular septa. Pulmonary abnormalities were predominantly basal and posterior in distribution, without pleural effusion or mediastinal lymph node enlargement (Fig. 3).

Laboratory controls on the 11th day of hospitalization showed increased result of CRP $(59.5 \mathrm{mg} / \mathrm{dL})$, but clinically he was asymptomatic. Antibiotic therapy was then replaced for clarithromycin $(15 \mathrm{mg} / \mathrm{kg} /$ day IV, for 5 days), with decrease of CRP levels after 5 days $(0.9 \mathrm{mg} / \mathrm{dL})$. D-dimer levels were 806 $\mathrm{ng} / \mathrm{dL}$ and $552 \mathrm{ng} / \mathrm{dL}$ on the 13th and 16th day of hospitalization, respectively.

A new blood culture collected on the 11th day of hospitalization was negative and had no bacterial growth again. The therapy with clarithromycin was then suspended on the fifth day of antibiotic. A new echocardiogram was done on the 15th day of hospitalization, with same changes previously described, maintaining normal coronary artery diameter. He was discharged on the 17th day of hospitalization and he has been followed up.

\section{Discussion}

We described a case of a Down syndrome newborn patient who developed flu-like syndrome at 26 days of life, probably transmitted by his parents, who also had the same symptoms. He was admitted to an ICU, where he received supportive care and underwent antibiotic therapy with ampicillin and gentamicin. His clinical condition improved. However, there was laboratory worsening during treatment, and antibiotic therapy was replaced for clarithromycin, with a fall in CRP afterwards. He had positive RT-PCR test for COVID-19 and imaging tests highly suggestive of this disease.

Patients with trisomy 21 could have more severe disease due to dysregulation of the immune response [9]. The patient involved in our study presented mild respiratory symptoms and thermal instability with favorable evolution.

Other cases of COVID-19 in newborns have been de-

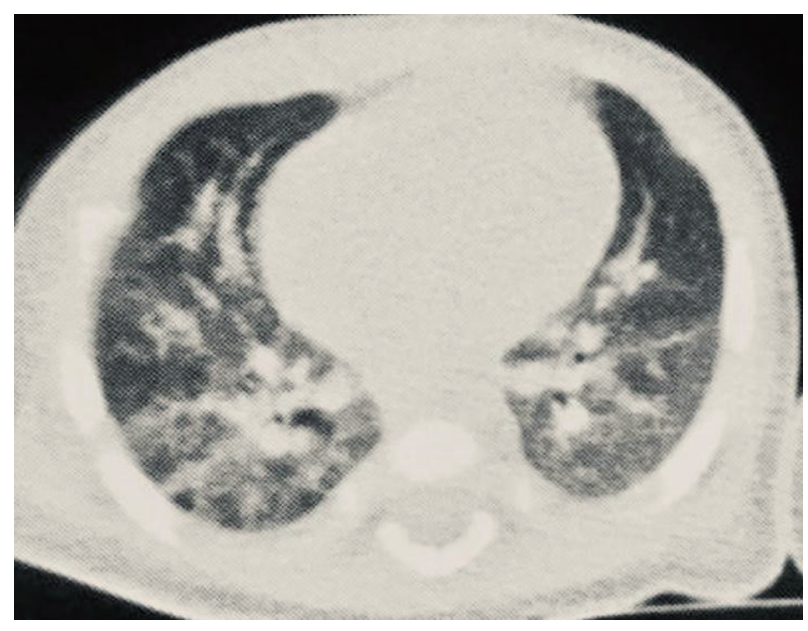

Figure 3. Chest computed tomography.

scribed with often mild presentation. The first case of infection reported was in a 39-week newborn, who was 17 days old when he was admitted to the hospital [10], but no other cases of newborns with Down syndrome were identified in the studied literature. He had sneezing and difficulty breastfeeding a week earlier. His parents had also cough and fever 3 days before admission. The newborn presented fever $\left(37.8^{\circ} \mathrm{C}\right)$, diarrhea and vomiting, without respiratory distress. He had a positive RT-PCR result in anal and oropharyngeal swab.

It was also reported a case of 26-week premature newborn whose mother had flu-like symptoms 1 day after delivery, with confirmation of COVID-19 infection. The newborn had a positive test for this disease at 7 days of life and had leukopenia and lymphopenia. In addition, he had bilateral nonspecific infiltrate in chest radiography performed with 17 days of life [11]. The newborn had no respiratory symptoms or hemodynamic instability because of COVID- 19 .

In a cohort study with 33 newborns born to mothers with confirmed COVID-19 infection, three of them had the disease, two of which had mild respiratory symptoms and one required non-invasive ventilatory support, but this one also had other risk factors for respiratory distress, such as prematurity and bacterial co-infection [12]. A case report described the clinical course of four newborns infected with COVID-19 whose mothers also had confirmed disease, reported that the main newborn symptoms were fever, respiratory distress and cough, and they needed just support care, without requiring ventilatory support or admission to the ICU [13]. Three of them had increased lung marking in chest CT. Another study involving children of different ages, included three newborns, whose chest CT showed no changes [14].

Chest CT has been used in patients with COVID-19 due to its high sensitivity [15]. Changes in CT tend to be less frequent in children, in addition to have lesser extent compared to adults [16].

We had some research limitation, like not have D-dimer test result at hospital admission and lack of coronavirus test in patient's parents. Further studies are needed to improve understanding of the relationship between COVID-19 infection and Down syndrome. 


\section{Conclusions}

We reported a case of COVID-19 in a Down syndrome newborn. Transmission occurred horizontally from parents. The symptoms included fever, runny nose and mild dyspnea. He received supportive care associated with antibiotic therapy, without the need of respiratory support. Chest radiography showed mixed interstitial and airspace opacities, and chest CT showed ground glass-opacities. He recovered by the end of this study and was discharged on the 17th day following admission.

\section{Acknowledgments}

We thank the parents of the newborn described for allowing us to share information about their son, and thank Dr Jose Antonio Koury Alves Junior, pediatric infectious diseases specialist for orientation about COVID-19 infection.

\section{Financial Disclosure}

None to declare.

\section{Conflict of Interest}

None to declare.

\section{Informed Consent}

We have obtained informed consent from the patient's guardians of this study.

\section{Author Contributions}

ACRL, SMS, DFAS, RSBR, BDO, TOCM, AGC, and KCC participated in the management of the patient and gave substantial contributions to this work. AFS contributed to the interpretation of the image results. GCLP wrote the manuscript with support from ACRL, SMS, DFAS, AFS, RSBR, BDO and TOCM. AGC and KCC were responsible in supervising the study and all authors revised it critically. Each author has given final approval of the final version of this study.

\section{Data Availability}

We declare that any inquiries regarding supporting data availability should be directed to the corresponding author.

\section{References}

1. De Rose DU, Piersigilli F, Ronchetti MP, Santisi A, Ber- sani I, Dotta A, Danhaive O, et al. Novel Coronavirus disease (COVID-19) in newborns and infants: what we know so far. Ital J Pediatr. 2020;46(1):56.

2. Soraya GV, Ulhaq ZS. Interleukin-6 levels in children developing SARS-CoV-2 infection. Pediatr Neonatol. 2020;61(3):253-254.

3. Lu Q, Shi Y. Coronavirus disease (COVID-19) and neonate: What neonatologist need to know. J Med Virol. 2020;92(6):564-567.

4. Dong L, Tian J, He S, Zhu C, Wang J, Liu C, Yang J. Possible vertical transmission of SARS-CoV-2 from an infected mother to her newborn. JAMA. 2020.

5. Vivanti AJ, Vauloup-Fellous C, Prevot S, Zupan V, Suffee C, Do Cao J, Benachi A, et al. Transplacental transmission of SARS-CoV-2 infection. Nat Commun. 2020;11(1):3572.

6. Coperchini F, Chiovato L, Croce L, Magri F, Rotondi M. The cytokine storm in COVID-19: An overview of the involvement of the chemokine/chemokine-receptor system. Cytokine Growth Factor Rev. 2020;53:2532.

7. Jose RJ, Manuel A. COVID-19 cytokine storm: the interplay between inflammation and coagulation. Lancet Respir Med. 2020;8(6):e46-e47.

8. Hennon TR, Penque MD, Abdul-Aziz R, et al. COVID-19 associated Multisystem Inflammatory Syndrome in Children (MIS-C) guidelines; a Western New York approach [published online ahead of print, 2020 May 23]. Prog Pediatr Cardiol. 2020:101232.

9. Espinosa JM. Down syndrome and COVID-19: a perfect storm? Cell Rep Med. 2020;1(2):100019.

10. Zeng LK, Tao XW, Yuan WH, Wang J, Liu X, Liu ZS. [First case of neonate infected with novel coronavirus pneumonia in China]. Zhonghua Er Ke Za Zhi. 2020;58(0):E009.

11. Piersigilli F, Carkeek K, Hocq C, van Grambezen B, Hubinont C, Chatzis O, Van der Linden D, et al. COVID-19 in a 26-week preterm neonate. Lancet Child Adolesc Health. 2020;4(6):476-478.

12. Zeng L, Xia S, Yuan W, Yan K, Xiao F, Shao J, Zhou W. Neonatal early-onset infection with SARS-CoV-2 in 33 neonates born to mothers with COVID-19 in Wuhan, China. JAMA Pediatr. 2020.

13. Zhang ZJ, Yu XJ, Fu T, Liu Y, Jiang Y, Yang BX, Bi Y. Novel coronavirus infection in newborn babies aged $<28$ days in China. Eur Respir J. 2020;55(6).

14. Xia W, Shao J, Guo Y, Peng X, Li Z, Hu D. Clinical and CT features in pediatric patients with COVID-19 infection: different points from adults. Pediatr Pulmonol. 2020;55(5):1169-1174.

15. Wen Z, Chi Y, et al. Coronavirus disease 2019: initial detection on chest CT in a retrospective multicenter study of 103 Chinese subjects. Radiol Cardiothorac Imaging. 2020;2(2):e200092.

16. Chen A, Huang J, et al. Differences in clinical and imaging presentation of pediatric patients with COVID-19 in comparison with adults. Radiol Cardiothorac Imaging. 2020;2(2):e10.1148. 